\title{
Nerve Root
}

National Cancer Institute

\section{Source}

National Cancer Institute. Nerve Root. NCI Thesaurus. Code C54024.

One of the two bundles of nerve fibers (dorsal and ventral roots) emerging from the spinal cord that join to form each spinal nerve. 